atterwards feltanotherdart, worse than before, and something seemed to slip up, and he felt relieved and went to sleep. The lower margin of the liver has receded an inch and a half higher up from the point previously noted, and the pain and tenderness are much relieved. Continue treatment.14th: The liver has receded in the right mammary line to its normal position under the ribs, and the left lobe is now nearly of normal dimensions. Temperature normal; pulse 74; bowels regular. Pain and tenderness over the hepatic region much diminished, and medicine still acts characteristically, but its action is not so marked. Continue treatment, and low diet as before.-16th: Pain and tenderness gone. Liver enlargement entirely reduced. The local action of the medicine is not now so marked. The sensation of "pins-and-needles," commencing in the centre of the lumbar region, reaches only to a point an inch from the right mammary line in the course of the costal arch. Continue treatment. -20 th : Doing well, Medicine produces no sensible action. No pain or tenderness anywhere, on pressure or movement. Countenance clear and bright. Colour returning to face. Continue treatment. - 26th : Doing well; chloroide of ammonium (ten grains) given thrice daily. To have chicken diet. Allowed up for half an hour daily.30th: Discharged from hospital quite well, but a little weak. To attend hospital as a convalescent for a few days.

The above case furnishes a good example of that state of disordered liver-well described by Annesley more than seventy years ago-so common in the stations of the Madras Presidency, which, commencing in imperfect discharge of the liver functions, when long continued terminates in congestion of the portal veins and engorgement of the ducts conveying the bile from the secretory structure of the organ. If this stage or form of disease be neglected, or only partially recovered from, it will terminate in a longer or shorter time, according to circumstances, in inflammatory action of a subacute kind with marked tendency to suppuration, in a limited portion or portions of the parenchyma. But in tropical hepatitis, no matter what may be the stage, the ammonium chloride is still the one special remedy for the specific disease, as I have fully shown, and amply confirmed by the statistics and cases published in my monograph. In the Indian Medical Gazette of July 1st, 1881, will be found further statistics on the subject; but as this paper is, I fear, already rather long, I must reserve what I have to say on that point for a future occasion.

Lymington, Hants.

\section{TWO CASES OF EMPYEMA.}

\section{BY JAMES W. FRASER, M.D. C.M. EDIN., M.R.C.S. ENG.}

THe following almost parallel cases of empyemaillustrate the well-known superiority of the treatment by early incision and dry antiseptic dressing.

CASE 1,-Ellen J. C- aged eight years, was first seen on April 15th, 1886, in an acute febrile condition, depending apparently on the inhalation of sewer gas. This was followed by left-sided pleurisy with effusion, which increased in spite of treatment until May 13 th, when the heart was found to be beating entirely to the right side of the sternum. Aspiration was therefore employed on that date, and the effusion, which was serous, was removed, the heart returning to its proper position, or nearly so. The fluid, however, reaccumulated; but the aspiration had had such a demoralising effect on the parents, and the child herself was so unmanageable, that when further operative interference was declined it was not strongly urged. The effusion increased, becoming purulent, and pointed in the mid-axillary line in the sixth interspace, the opening taking place spontaneously on July 16th. Preparations for the discharge were made by washing the skin with carbolic lotion and covering the side with a thick layer of corrosive sublimate wood-wonl wadding. No further antiseptic precautions, beyond the insertion of a drainage tube and in the later weeks of the treatment washing out the side with weak idine water, were taken, but the discharge never became offensively septic; still it was so abundant as to require the dressings to be changed daily until Aug. 10th. It was not until September 11th that the child could be sent from home, -even then with a small discharging sinus. She bas since been seen, and the chest appears equally resonant on both sides, nor is there any lateral currature.
CASE 2.-Charles P-, aged nine years, had a very slight attack of scarlet fever, the rash appearing on March 31st, 1887. He progressed favourably until early in April, when he apparently caught cold, and the signs of leftsided pleurisy were discovered on April 13th. The effusion increased rapidly, and the apex beat of the heart on the 15th was to be felt to the right of the ensiform cartilage. The aspirator was used on that day, and the effusion was found to be purulent. The fluid reaccumulated, and the boy passed into a hectic condition, with diarrhoea and an evening temperature of $102.5^{\circ}$. Though this patient was fully as unmanageable as the former, the parents were more reasonable, and their consent to opening the side was readily obtained. This was therefore done on the 21st, cocaine being used as the anæsthetic, and full antiseptic precautions taken. The carbolic spray was used, and when the natural flow of the matter had ceased, a further quantity was removed by the method of perfiation described by Dr. Ewart in THe LANCET (vol. ii. 1886, p. 226). The incision was in the sixth interspace behind the posterior axillary line. A large-sized drainage tube was introduced, and a dry dressing of corrosive sublimate wood wool applied. The dressing was only changed when the discharge came through, which for the first week was night and morning. Signs of carbolism were seen on the $24 \mathrm{th}$, depending partly on the liberal use of the spray and partly on the carbolic lotion used to purify the air used in the perflation. Tincture of iodine was substituted for the latter, and the dressings were performed as rapidly as possible and the carbolism disappeared. The temperature fell to normal on the day after the operation, and all went on well until May 2nd, when the hectic fever and diarrhœea recurred. These appeared to be caused by the dressings blocking the mouth of the tube, for when this was remedied the use of aromatic sulphuric acid and tincture of bark soon reduced the temperature and controlled the bowels. On May 20th the tube was found to have been pushed out, and the only sign of the disease was a sinus less than half an inch deep. The boy is now perfectly well and the lung is evidently well expanded, though the left side is still less resonant than it should be.

From the opening of the abscess to the time of full recovery in the first case was seven weeks, from the incision to the full recovery in the second four weeks; a clear saving of three weeks by antiseptic incision and dry treatment, to say nothing of the saving of all the time occupied in the natural passage of the pus to the surface in the former. Two minims of a 10 per cent. solution of cocaine was the anæsthetic used in the second case, and the boy, though he roared lustily all the time, confessed afterwards that he never felt the knife. In order, if possible, to obtain quietness by removing the pain even of the prick of the subcutaneous needle, a 5 per cent. ointment of cocaine in lanoline was rubbed into the side, but only appeared to deaden the pain; possibly a 10 per cent, ointment would have been more successful. The use of tincture of iodine instead of carbolic lotion in the wash bottle of the perflation apparatus is also important by reducing the danger of carbolism. Hull.

\section{d athrox}

\section{HOSPITAL PRACTICE, BRITISH AND FOREIGN.}

Nulla autem est alia pro certo noscendi via, nisi quamplurimas et moroorum et dissectionum historias, tum aliorum tum proprias collectas habere, et inter se comparare.-MoBgaGNI De Sed. et Caus. Morb., lib. iv. Procmium.

\section{HOSPITAL FOR SICK CHILDREN.}

TWO CASES OF CALCULUS; OPERATION; REMARK8.

(Under the care of Mr. JoHN H. MoRgan.)

As is well known, a very great revulsion has taken place of late years in the treatment of calculus at all ages, and the more general application of lithotrity, with complete evacuation, has proved so satisfactory in its results in adults that surgeons are turning their attention to the question of its applicability in the case of children. Whatever the verdict that may be arrived at in future, cases will arise in 